Article

\title{
Retirement and Management of Diabetes in Medically Underserved Patients with Type 2 Diabetes: Preliminary Findings and Literature Review.
}

\author{
Iyabo Obasanjo ${ }^{1 *}$ and William Mann² \\ 1Department of Kinesiology and Health Sciences, College of William and Mary, Williamsburg, VA 23187, USA \\ 2Medical Director, Olde Towne Medical and Dental Center, Williamsburg, VA 23188, USA
}

Received April 7, 2019; Accepted May 20, 2019

\begin{abstract}
Background: Studies have found that diagnosis of Type 2 diabetes increases the risk of early retirement in the high-income countries. In this study, we examined the levels of glycated hemoglobin (HbA1c) by employment status to determine if early retirement confers a benefit to managing diabetes.
\end{abstract}

Methods: The data was from a primary care center serving the uninsured and medically underserved in the greater Williamsburg area in the State of Virginia. Plasma concentration of HbA1c (\%) from the last visit was used to measure the average level of blood glucose and as an assessment test for glycemic control in people with diabetes. Data analyses were carried out using general linear regression with $\mathrm{HbA1c}$ as the dependent variable and employment status, gender and age as the independent variables; and the interaction of gender and employment status and interaction of age and employment status were assessed to control for potential confounding factors.

Results: The results showed that males tended to have a higher level of HbA1c; overall age was negatively associated with the levels of HbA1c; there was a significant difference in the mean levels of HbA1c between the retired people and people working part-time $(p=0.032)$. After controlling for age and gender in the multiple linear regression analysis, employment status became non-significantly associated with HbA1c levels. Post hoc analysis showed a difference in HbA1c between individuals working part-time (the highest HbA1c group) and the full-time employed at a marginal significance ( $p=0.0823$ ). While almost 20 years older, the retired people had the lowest level of HbA1c. However, the mean level of HbA1c was no longer significantly different from that in other groups, probably because age explained much of this variation in the levels of HbA1c among employment status. Multiple regression analysis showed that age was negatively associated with the levels of $\mathrm{HbA1c}$ (The retired people mainly derived Beta $=-0.046, \mathrm{p}<0.0001$ ).

Conclusion: In this underserved population, the $\mathrm{HbA1c}$ level is the lowest in people after retirement, even though they are older. Our study indicates that retirement may be a beneficial factor to the management of diabetes, which warrants further investigation.

\section{KEYWORDS}

Retirement, type 2 diabetes, underserved populations, HbA1c

\section{INTRODUCTION}

Diabetes is a group of metabolic diseases with excessive level of blood glucose over a prolonged period (1). Type 2 diabetes is the most common form of the disease and is caused by the body not making enough or appropriately using insulin, a hormone that helps glucose get into cells to be processed into energy (2). Having too much glucose in the blood may cause severe problems, including damaging eyes, kidneys, and nerves; and untreated diabetes can also cause heart disease and stroke. Women who are pregnant are may develop diabetes, which is called gestational dia-

\footnotetext{
*Correspondence: Iyabo Obasanjo; e-mail: iobasanjo@wm.edu
}

betes. The prevalence of diabetes is increasing in the US and globally, and the increasing rates of overweight and obesity in people and the aging of populations drive this trend.

Diabetic conditions may require long-term management of blood glucose, which is defined as to keep levels of blood glucose as close to normal as possible by balancing food intake with medication and activity. Low income and low educational attainment have been associated with the increased risk of hypoglycemia in diabetes (3), which may be caused by taking too much insulin or other diabetes 
medications, reduced eating foods, or doing more exercise. Both diabetes and hypoglycemia in diabetes harm employment such as early labor-force exit and income (4-8). In this study, we examined the level of $\mathrm{HbA1c}$ as the measure of diabetes management, by employment status. There are reports that people diagnosed with diabetes start an exercise regimen but that this often tapers off over time with aging $(9,10)$. Retired people with diabetics could either have more time to do physical exercise, which improves the levels of their hemoglobin A1c or taper off over time due to aging. Many patients with diabetes also have comorbidities and are on several medications. The number of co-morbidities and medications would be expected to increase with age, which could inhibit their ability to manage their diabetes through exercise. With the aging global population, more people than ever before will have diabetes when they retire, and therefore, understanding management of diabetes after retirement is essential for healthy aging.

\section{METHODS}

Using medical records from a clinic that serves a medically under-served population, we examined the effect of employment status and retirement on the management of diabetes. The data was from the Olde Towne Medical and Dental Center in Williamsburg, Virginia, which is a primary care center providing health services to the uninsured and underinsured in the Greater Williamsburg area. The Institutional Review Board approval was obtained from the Institutional Review Board of the College of William and Mary. The plasma level of HbA1c was based on the measurement in the last visit to the clinic. Blinded data for all patients with diabetes in the clinic database was downloaded into an Excel spreadsheet.

Data collected included age, the number of co-morbidities, number of medications, plasma levels of hemoglobin A1c (\%), gender, and residence address, which was mapped to the distance from the clinic. Hemoglobin is the part of red blood cells that carries oxygen from the lungs to the rest of the body. Because the lifespan of a red blood cell is about 100 to120 days, an HbA1c test can measure the average amount of glucose attached to hemoglobin over the past three months. HbA1c is used for making a diagnosis of diabetes. Typically, a diagnosis of diabetes is made when HbA1c about $6.5 \%$ or higher, and pre-diabetes when the plasma HbA1c levels were between 5.7 and 6.4\%.

Linear regression analysis was performed with the outcome variable levels of HbA1c measured as a percentage, and the independent variables were employment status, gender, and age. The model was defined as HbA1c $=\alpha+$ $\beta_{1}{ }^{*}$ age $+\beta_{2}{ }^{*}$ gender $+\beta_{3}{ }^{*}$ employment status; possible interactions between age and employment status and between gender and employment status were also assessed. Statistical analyses were carried out using XLSTAT in Excel and SAS.

\section{RESULTS}

Table 1 gives the characteristics of subjects by employment status. Of the total 413 participants, there were 40 retired people (9.69\%), 194 unemployed (46.97\%), 95 working full time (23\%), 71 working part-time (17.19\%) and 13 no available information on employment (3.15\%), who were likely self-employed. The mean age of the retired people was 74.52 years, which was 20 years older than people with another employment status. The median numb-er of co-morbidities and medications in the retired people were 4 and 10, respectively, which were not significantly higher, given that their age was 20 years older, compared with other groups. People who worked full-time had a rela-tively low proportion of females (46.32\%) compared with the people retired (67.5\%) and unemployed (63.93\%); women were more predominant in working part-time $(78.87 \%)$.

Table 1. Characteristics of subjects in five employment groups $(\mathrm{N}=413)$

\begin{tabular}{|c|c|c|c|c|c|c|c|}
\hline \multirow[b]{2}{*}{ Employment status } & \multirow[b]{2}{*}{$\mathrm{N}$} & \multirow[b]{2}{*}{$\%$} & \multirow[b]{2}{*}{ Mean age } & \multirow[b]{2}{*}{ Co-morbidities* } & \multirow[b]{2}{*}{ Medications* } & \multicolumn{2}{|c|}{ Females, \% } \\
\hline & & & & & & $\mathrm{n}$ & $\%$ \\
\hline Retired & 40 & 9.69 & 74.52 & 4 & 10 & 27 & 67.50 \\
\hline Unemployment & 194 & 46.97 & 54.50 & 4 & 7 & 124 & 63.92 \\
\hline Part-time employed & 71 & 17.19 & 50.73 & 3 & 5 & 56 & 78.87 \\
\hline Undefined (mainly self-employed) & 13 & 3.15 & 52.00 & 3 & 7 & 5 & 38.46 \\
\hline
\end{tabular}

Note: * median number of co-morbidities and medications

We noted that the levels of HbA1c were different by employment status (Table 2). The overall crude mean level of HbA1c was 7.9\% (min-max: 4.6-15; $\mathrm{SD}=2.3$ ), mean age was 55.2 years (min-max: 22-98; $S D=12.8$ years). The retired people tended to have a lower level of HbA1c (Mean= 7.23\%; $\mathrm{SD}=2.06$ ) and even with smaller min-max range (4.9-12.9\%); whereas the part-time employed had the highest level of HbA1c (Mean=8.21\%; SD=2.46). There was a significant difference in the mean level of plasma HbA1c between the retired and the part-time employed ( $p=$ 0.032); no significant difference in the mean levels of HbA1c was observed between other employment status based on the Analyses of Variance (ANOVA). We also noted that males had a higher level of HbA1c (Mean=8.1\%; $\mathrm{SD}=2.3$ ) than females (Mean=7.12\%; $\mathrm{SD}=2.31$ ).

Because the sample was highly heterogeneous, we examined the relationship between $\mathrm{HbA1c}$ and age by employment status (Figure 1). We noted a consistent trend across a different group of employment status that the levels of HbA1c tended to be negatively associated with age in all groups, and the most influential association seemed in the unemployed people and people working full time. However, the correlations between age and HbA1c was flatter in people who worked part-time and had the highest mean level of $\mathrm{H} 1 \mathrm{~A} 1 \mathrm{c}$, as well as the retired people who had the lowest mean level of HbA1c. 
Table 2. Summary of plasma $\mathrm{HbA1c} \%$ ) in patients with Type II diabetes by employment status and gender

\begin{tabular}{llrrrrrr}
\hline Variable & Code & $\mathrm{n}$ & Mean & Median & SD & Min & Max \\
\hline $\begin{array}{l}\text { Overall } \\
\text { Gender }\end{array}$ & & 413 & 7.87 & 7.0 & 2.31 & 4.6 & 15 \\
& Male & 157 & 8.10 & 7.5 & 2.30 & 4.8 & 15 \\
& Female & 256 & 7.12 & 6.8 & 2.31 & 4.6 & 15 \\
Employment & & & & & & \\
& Retired & 40 & 7.23 & 7.5 & 2.06 & 4.9 & 12.9 \\
& Unemployed & 194 & 7.92 & 7.0 & 2.19 & 4.6 & 15 \\
& Fulltime & 95 & 7.78 & 6.8 & 2.46 & 5.0 & 15 \\
& Part-time & 71 & 8.21 & 6.9 & 2.46 & 5.2 & 15 \\
& Undefined (mainly self-employed) & 13 & 8.08 & 9.9 & 2.15 & 5.3 & 12.4 \\
\hline
\end{tabular}

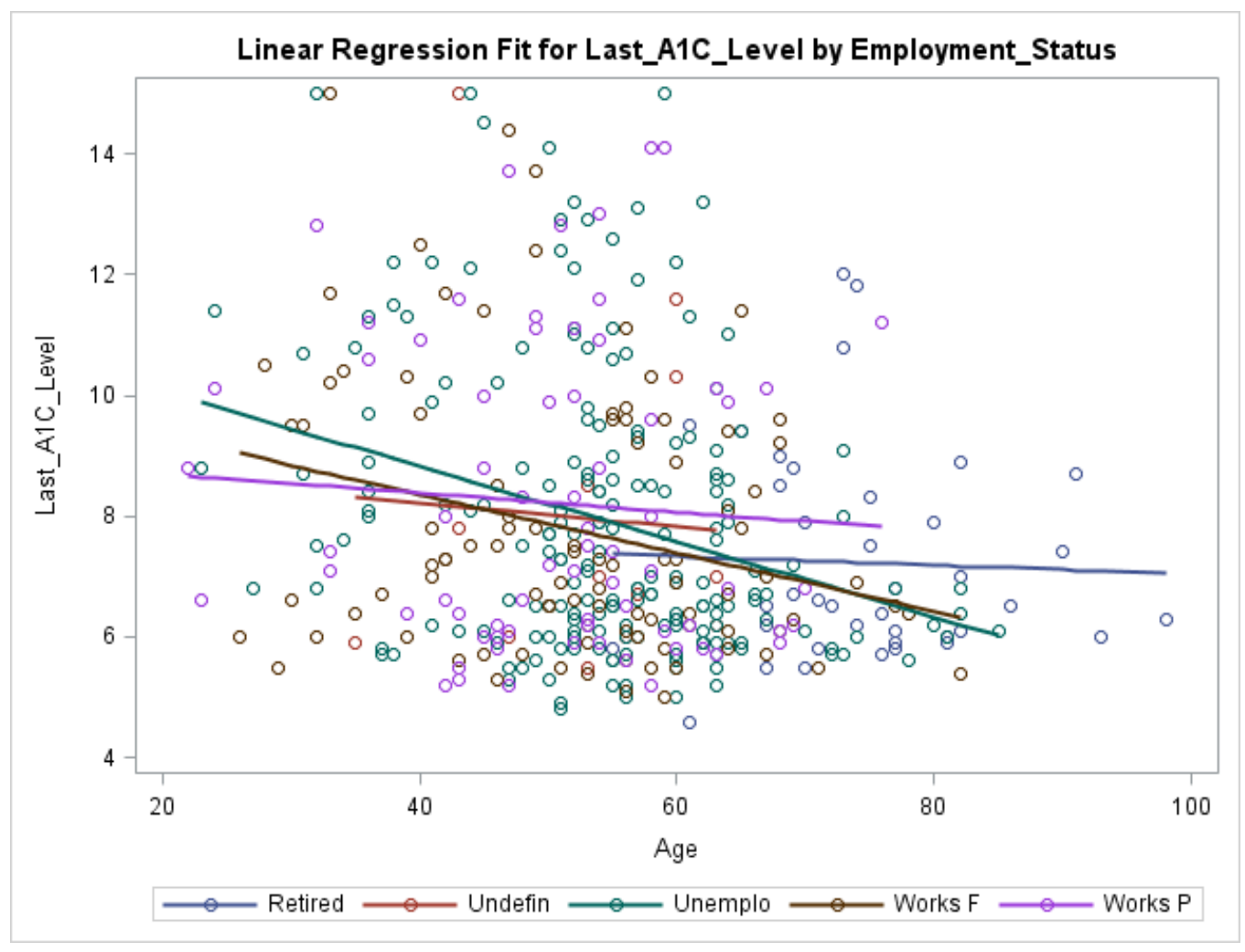

Figure 1. Linear regression fitted line of levels of $\mathrm{HbA1c}$ and age by employment status. Retired, retired people; Undefin, undefined category; Unemplo, unemployment; Works F, worked full-time; Works P, worked part-time.

We further performed multiple linear regression analysis while controlling for age, gender, employment status, and an inter-action term of gender by employment because the type 2 diabetes is more prevalent in males (11) and females predominated in part-time work with the highest level of $\mathrm{HbA} 1 \mathrm{c}$ (mean=8.21\%; SD=2.46) in our data (Table 3). We found that the overall model was significant and that age was negatively associated with levels of $\mathrm{HbAlc}$ significantly (Beta $=-0.46 ; p<0.0001$ ); and females tended to have a lower level of HbA1c (Beta $=-0.51 ; p=0.0291)$ compared with males. However, there was no significant difference in the mean level of HbA1c between employment statuses ( $p=$ $0.5504)$; and no significance was found for the inter-action between employment status and age $(p=0.450)$ and the interaction between employment status and gender ( $p=$ 0.735).

Based on the model with an interaction term of age and employment status, we performed a post hoc test for the least-square mean of $\mathrm{HbA1c}$ by employment status (Figure 2). Except that there was a difference in the leastsquare mean of $\mathrm{HbA} 1 \mathrm{c}$ between work full-time and parttime at a marginally significant level $(p=0.0823)$, we found no significant difference in the mean level of HbA1c among other groups ( $p=0.3049)$, although the retired people still had the lowest while people working part-time had the highest level of mean HbA1c. This is 
probably because that age had accounted for the retirement effect on $\mathrm{HbA} 1 \mathrm{c}$.

Table 3. Multiple linear regression analysis of levels of HbA1c with age, gender and employment status.

\begin{tabular}{|c|c|c|c|c|c|c|}
\hline Variable & Code & Beta & SE & t Value & $P$ & $P^{*}$ \\
\hline \multirow{3}{*}{$\begin{array}{l}\text { Age } \\
\text { Gender }\end{array}$} & Intercept & 11.0261 & 0.6119 & 18 & $<.0001$ & \\
\hline & Years & -0.0475 & 0.0101 & -4.72 & $<.0001$ & \\
\hline & Female & -0.5103 & 0.2329 & -2.19 & 0.0291 & \\
\hline \multirow[t]{6}{*}{ Employment Status } & & & & & & 0.5504 \\
\hline & Retired & 0.0934 & 0.5040 & 0.19 & 0.8531 & \\
\hline & Undefined & -0.3498 & 0.6833 & -0.51 & 0.6090 & \\
\hline & Unemployment & -0.1899 & 0.3152 & -0.6 & 0.5471 & \\
\hline & Work full time & -0.5348 & 0.3596 & -1.49 & 0.1378 & \\
\hline & Work partime & 0.0000 & & & & \\
\hline
\end{tabular}

Note, $\mathrm{p}^{*}$, the overall p-value for association with $\mathrm{HbA} 1 \mathrm{c}$

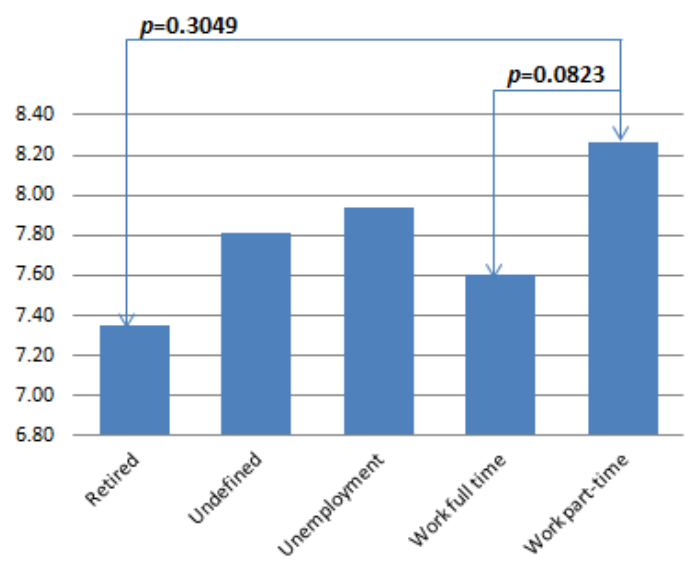

Figure 2. Least square means of HbA1c by employment status based on multiple linear regression with an interaction term of age and employment.

\section{DISCUSSION}

Several papers have investigated the effect of work on the management of Type 2 diabetes, and its impact seems to be that people with diabetes tend to leave employment and retire early. Whether retirement results in better control of diabetes for patients that are retired have not been examined. In our limited data from one medical facility serving the uninsured and underinsured, we found that people of older age, who were mainly retired people have better management of their HbA1c levels.

Walzer theoretically evaluated the influence of early retirement on healthcare budget and insurance premiums and found that it might not be desirable for insurance companies and countries to have patients with diabetes retire early(12). Studies using two independent datasets show that levels of HbA1c are increased with age in healthy populations without known diabetes (13). In addition, dia- betes is a progressive disease, but retirement could be an effective intervention to delay progress.

While studies have generally found that patients with diabetes retire earlier, Miah and Wilcox-Gok (14), found that patients with diabetes and other chronic illnesses accumulate fewer assets over time and so tend to retire later. Their study did not show a reduction in activities of daily living for people with diabetes and given the effective medications available and if combined with diet and exercise should lead to the effective long-term management of diabetes. Their result is supported by a study in Finland (15), showing that patients with diabetes work about two years longer than people not diagnosed with diabetes do. This finding may be related to the superior health system in Finland, which provides effective management of diabetes to every citizen and to having flexible jobs situations that allow people the opportunity to stay employed and manage their disease. It would be interesting for highincome countries with aging populations to evaluate the effect of job change on the control of diabetes to allow such patients to stay in the workforce. An Australian study also found that diabetes reduced income and that people with diabetes tend to retire early (16).

However, an individual's decision to retire is based on many factors, including the type of job, retirement savings, family support, or other types of retirement funding as well as age. Patients with diabetes as older adults tend to have clinical complexity or cognitive impairment that may have reduced their ability to do exercise or manage their diabetes $(17,18)$. Using Finnish data, Kivimaki et al-found that retirement was associated with an increased likelyhood of poor adherence to antidiabetic drugs in men and associated with poor adherence to antihypertensive medications in both men and women (19).

The theoretical argument can be made that since people with chronic diseases are likely to die earlier, there is a benefit to having them retire earlier; however, if retirement then allows them to manage their chronic conditions better, their lives might not be shortened. Rodriguez has 
posited that since people with chronic diseases at low social and economic status die at younger ages, their contribution to economic participation is lost (20). As the burden of chronic non-infectious diseases grows with aging populations, countries will have to find a way to encourage active aging. It is worth examining in future studies what types of jobs lead to better management of diabetes and advising a change of employment rather than early retirement for low-income people with diabetes. It may also be a policy intervention for governments to provide people with chronic diseases such as diabetes with training to change jobs to less stressful ones or posts that are more conducive to the management of their condition. As the population ages, the prevalence of diabetes will continue to rise, and having diabetic patients stay in the working population will be critical for society.

People over 50 years with diabetes have higher levels of physical disability and faster rates of deterioration of the physical ability compared with people of the same age without diabetes; and the difference is more pronounced in women, racial minorities and people with lower levels of education with diabetes compared to the same group without diabetes (21). The deterioration in physical ability explains why studies have found higher rates of not working and retirement in diabetes patients. Vijan et al. (22) found that people with diabetes are more likely to be disabled, retired, or taken sick days off work compared to people of the same age not diagnosed with diabetes. They estimated approximately an annual economic loss of one billion dollars a year due to the decline in economic productivity among people with diabetes. The rate of diabetes has increased significantly since their analyses in 2004, and the loss will be higher today. It is, therefore, important to find ways of having people with diabetes stay employed and manage their diabetes while at work.

Certain types of jobs where workers have low control are associated with increased risk of diabetes (23). A way forward could be that after diagnosis with diabetes, people could move to other types of jobs that offer more control such as jobs where they can work from home or schedule on their own time rather than retire. KouwenhovenPasmooij et al. (24) found that while workers with diabetes had increased probability of early retirement and getting disability benefits, this probability increased mostly for people with low control jobs. Whether jobs can be generated for people with diabetes that allows them to stay in the workforce depends on how co-workers accept such programs and if co-workers were willing to have changes in the workplace to assist diabetes patients to remain at work in Denmark (25). This may not be the case globally as things like taking blood sugar measurements at work and thriving to eat differently from peers has been associated with stigmatization (26). Mutambudzi et al. (27) also found that jobs with more effort than reward were associated with a diagnosis of diabetes. How to change work environments for an aging population with more prevalence of chronic diseases such as diabetes especially in low paying jobs where people have less control will be a challenge for the high-income countries in the coming years.
Social support has been found to improve diabetes management in the middle-aged and elderly patients with Type 2 diabetes (28) and people in retirement should be able to do more exercises and eat healthier but also find time to associate with family and friends in situations that leads to less stress and more communal circumstances. In our study with small limited data, there is an indication that retirement could confer some benefit for older people with diabetes.

\section{Limitations}

Our data from medical records were not collected for the sole purpose of research. One major limitation of this study is that we did not obtain longitudinal data and only used the last HbA1c for patients to determine if patients had their diabetes under control and therefore effects over time could not be determined.

\section{CONCLUSION}

Our study showed that older diabetics who are mainly retired people have better management of their diabetes. Earlier studies have shown that people with diabetes retire early, and we show that retirement helps with the management of diabetes, indicating that retirement may be an effective intervention for diabetes, especially in the lowincome patients. As populations age, there may be a need for investigating alternatives to retirement such as job change to keep people employed and contributing economically.

\section{CONFLICT OF INTEREST}

We declare that there is no conflict of interest regarding the publication of this paper.

\section{ACKNOWLEDGMENTS}

We acknowledge Nandini Singh and Emma Freiling for the blinded data download, Moussa Dia for mapping the distance to residential addresses from clinic address and Kendra Robinson, the Diabetes Clinic Director at Olde Towne Medical and Dental Center who manages the diabetes patients at the clinic.

\section{REFERENCES}

1. Kharroubi AT, Darwish HM. Diabetes mellitus: The epidemic of the century. World J Diabetes. 2015;6(6):850-67.

2. American Diabetes A. Standards of medical care for pati-ents with diabetes mellitus. Diabetes Care. 2000;23 Suppl 1:S3242.

3. Berkowitz SA, Karter AJ, Lyles CR, Liu JY, Schillinger D, Adler $\mathrm{NE}$, et al. Low socioeconomic status is associated with increased risk for hypoglycemia in diabetes patients: the Diabetes Study of Northern California (DISTANCE). J Health Care Poor Underserved. 2014;25(2):478-90.

4. Rodriguez-Sanchez B, Cantarero-Prieto D. Performance of people with diabetes in the labor market: An empirical approach controlling for complications. Econ Hum Biol. 2017; 27(Pt A):102-13.

5. Minor T. An investigation into the effect of type I and type II diabetes duration on employment and wages. Econ Hum Biol. 2013;11(4):534-44. 
6. Herquelot E, Gueguen A, Bonenfant S, Dray-Spira R. Impact of diabetes on work cessation: data from the GAZEL cohort study. Diabetes Care. 2011;34(6):1344-9.

7. Rumball-Smith J, Barthold D, Nandi A, Heymann J. Diabetes associated with early labor-force exit: a comparison of sixteen high-income countries. Health Aff (Millwood). 2014; 33(1):110-5.

8. Cleal B, Poulsen K, Hannerz H, Andersen LL. A prospective study of occupational status and disability retirement among employees with diabetes in Denmark. Eur J Public Health. 2015;25(4):617-9.

9. Leung LA, Swaminathan S, Trivedi AN. Diabetes diagnosis and exercise initiation among older Americans. Prev Med. 2014;65:128-32.

10. Nothwehr F, Stump T. Health-promoting behaviors among adults with type 2 diabetes: findings from the Health and Retirement Study. Prev Med. 2000;30(5):407-14.

11. Sattar N. Gender aspects in type 2 diabetes mellitus and cardioetabolic risk. Best Pract Res Clin Endocrinol Metab. 2013; 27(4):501-7.

12. Walzer S. Early retirement and the influence on healthcare budgets and insurance premiums in a diabetes population. Vasc Health Risk Manag. 2007;3(3):331-41.

13. Dubowitz N, Xue W, Long Q, Ownby JG, Olson DE, Barb D, et al. Aging is associated with increased HbA1c levels, independently of glucose levels and insulin resistance, and also with decreased HbA1c diagnostic specificity. Diabet Med. 2014;31(8):927-35.

14. Miah MS, Wilcox-Gök V. Do the sick retire early? Chronic illness, asset accumulation, and early retirement. Applied Economics. 2007;39(15):1921-36.

15. von Bonsdorff MB, von Bonsdorff ME, Haanpaa M, Salonen M, Mikkola TM, Kautiainen H, et al. Work-loss years among people diagnosed with diabetes: a reappraisal from a life course perspective. Acta Diabetol. 2018;55(5):485-91.

16. Schofield D, Cunich M, Kelly S, Passey ME, Shrestha R, Callander E, et al. The impact of diabetes on the labour force participation, savings and retirement income of workers aged 45-64 years in Australia. PLoS One. 2015; 10(2): e0116860.

17. Feil DG, Zhu CW, Sultzer DL. The relationship between cognitive impairment and diabetes self-management in a population-based community sample of older adults with Type 2 diabetes. J Behav Med. 2012;35(2):190-9.
18. Blaum C, Cigolle CT, Boyd C, Wolff JL, Tian Z, Langa KM, et al. Clinical complexity in middle-aged and older adults with diabetes: the Health and Retirement Study. Med Care. 2010; 48(4):327-34.

19. Kivimaki M, Batty GD, Hamer M, Nabi H, Korhonen M, Huupponen $\mathrm{R}$, et al. Influence of retirement on nonadher-ence to medication for hypertension and diabetes. CMAJ. 2013; 185(17):E784-90.

20. Rodriguez JM. Health disparities, politics, and the maintenance of the status quo: A new theory of inequality. Soc Sci Med. 2018;200:36-43.

21. Chiu CJ, Wray LA. Physical disability trajectories in older Americans with and without diabetes: the role of age, gender, race or ethnicity, and education. Gerontologist. 2011; 51(1): 51-63.

22. Vijan S, Hayward RA, Langa KM. The impact of diabetes on workforce participation: results from a national household sample. Health Serv Res. 2004;39(6 Pt 1):1653-69.

23. Mutambudzi M, Javed Z. Job Strain as a Risk Factor for Incident Diabetes Mellitus in Middle and Older Age U.S. Workers. J Gerontol B Psychol Sci Soc Sci. 2016;71(6): 1089-96.

24. Kouwenhoven-Pasmooij TA, Burdorf A, Roos-Hesselink JW, Hunink MG, Robroek SJ. Cardiovascular disease, dia-betes and early exit from paid employment in Europe; the impact of work-related factors. Int J Cardiol. 2016; 215: 332-7.

25. Nexo MA, Cleal B, Hagelund L, Willaing I, Olesen K. Willingness to pay for flexible working conditions of people with type 2 diabetes: discrete choice experiments. BMC Public Health. 2017;17(1):938.

26. Browne JL, Ventura AD, Mosely K, Speight J. Measuring Type 1 diabetes stigma: development and validation of the Type 1 Diabetes Stigma Assessment Scale (DSAS-1). Diabet Med. 2017;34(12):1773-82.

27. Mutambudzi M, Siegrist J, Meyer JD, Li J. Association between effort-reward imbalance and self-reported diabetes mellitus in older U.S. workers. J Psychosom Res. 2018;104:61-4.

28. Nicklett EJ, Heisler ME, Spencer MS, Rosland AM. Direct social support and long-term health among middle-aged and older adults with type 2 diabetes mellitus. J Gerontol B Psychol Sci Soc Sci. 2013;68(6):933-43.

How to cite this article:

Obasanjo I and Mann W. Retirement and management of diabetes in medically underserved patients with type 2 diabetes: preliminary findings and literature review. Glob Clin Transl Res. 2019; 1 (2):78-83

Online access at: https://www.gcatresearch.com 